\title{
HOSPITAL ISOLATION.*
}

BY WILLTAM SCATTERTY, M.A., M.D.,

Medical Officer of Health for Keighley; President of the Yorkshire Branch of the Incorporated Society of Medical Officers of Health.

THE subject I have chosen for my paper is Hospital Isolation. I have been led to do so because it lends itself very readily to general discussion, and because the problems involved are of interest to every Medical Officer of Health. Many writers of late have approached the subject with diffidence, seeing that thousands of pounds have been spent and are being spent on the erection and maintenance of fever hospitals all over the country; and to question the utility or otherwise of hospital isolation at this stage, looks like locking the door after the horse is stolen. I would however deprecate such hesitancy, believing as I do that any investigation into the results derived from hospital isolation will strengthen our faith in isolation, although it probably will discover many weak points in our system of fever hospital administration.

It is not unlikely that many sanitarians entertained the hope that hospital isolation would stamp out, or at least very materially limit the spread of infections disease, and we must ask ourselves how far such optimism has been justified, and at the same time question the wisdom or justice of blaming hospital isolation for failing to do what was obviously ultra vires. There are many factors at work in spreading infection, which are untouched by isolating known or notified cases of fever, and to expect that an epidemic could be completely prevented or stopped without combating such factors is unreasonable. That isolation of all notified cases should materially diminish the spread by removing known foci of infection, is however a reasonable requirement, and if heavy expenditure has been incurred in providing hospital accommodation a corresponding return is to be expected and asked for.

The first to seriously open the campaign against hospital isolation was Dr. Marriott, of Nottingham, and later, Dr. Millard, who in February, 1901, tried to show that it failed materially to reduce the fatality or prevalence of scarlet fever, and further that such isolation was not merely negative in its results, but in many ways positively harmful. I have no intention of analysing the statistics which induced him to arrive at this conclusion. That has already been done by Dr. Kaye and others, but what I would like to hear discussed is

\footnotetext{
*Presidential Address, October 20, 1904.
} 
the charge of failure to meet reasonable expectation, and the cause or causes of failure if such exists; in other words, Is the principle, or the practice, of hospital isolation at fault? Given a number of facts or figures how many of us would deduce the same conclusion? For instance, Dr. Millard tells how in Leicester (1892) 144 scarlet fever patients were sent from hospital to make room for small-pox, and because no cases of fever occurred in any of the houses to which those patients were returned, he concluded that we must not limit the meaning of "return cases" solely to those of the same bousehold, leaving it to be inferred that these 144 cases might have infected their neighbours, even although their own households were immune. Quite so, but may we not make the further deduction that the neighbours would also have escaped if the 144 had still been isolated in hospital ? That surely must go to the credit side of the hospital account. We are further told (Public Health, February, 1902) that during the following two months 400 odd cases occurred, compared with 90 during the previous ten months. Granted that there were many susceptible children owing to there being no epidemic for years, it seems evident that the 144 foci were like torches set to fuel, and that the benefits of hospital isolation, so far as reduction of prevalence is concerned, in contrast to home treatment, were demonstrated lamentably. With regard to the reduction of mortality it is enough for me to know that hospital isolation reduces the prevalence of scarlet fever; that the mortality will fall pari passu requires no proof.

Dr. Kaye has I think fully shown the hopelessness of getting any satisfactory conclusion from a statistical comparison of towns differing widely from each other as well as from themselves in different years. He suggests that every Medical Officer of Health should rather compare the results, each in his own town, before and after the provision of hospital isolation. I am afraid the results as yet available are not reliable, owing to epidemic infuences and the short period from which most of us can draw comparisons. In my own borough we have had hospital isolation for seven years, and if we compare the numbers notified before and since, the comparison would simply be between an epidemic and a non-epidemic period. I am certain, however, that the epidemic which compelled the erection of a hospital could not have been controlled so successfully had no such provision been made for isolating many of the cases. With regard to the percentage of fatal cases before and since hospital isolation was practised, as well as among those treated at home compared with those treated in hospital, I find the results are distinctly favourable to the fever hospital.

In the campaign against isolation hospitals the frequency of " return cases" is kept prominently to the front. That such cases do occur is 
common knowledge, but may we not too readily grant that they are always of hospital origin? It is the experience of private practitioners (if not of hospital superintendents) that similar cases occur in private houses, and I believe with equal frequency. There is this difference, however, that a second case in private practice is generally accounted for by defective house disinfection, or by supposing that the second contracted infection, say at school, just as the first did; but when the primary case has recently come from hospital it saves trouble to call the second a "return case." Thus the blame is transferred from an indefinite and irresponsible cause either to the hospital superintendent, who is thought guilty of indiscretion or neglect, or to the hospital system which specializes in this particular phenomenon.

Let us now for a moment consider some of the causes which are said to produce these return cases. Premature discharge before desquamation is completed, need only be mentioned as an exceptional cause requiring no consideration. Otorrhoea and rhinorrhoea are much more likely causes, although these cannot always be attributed to hospital influences. A rhinorrhœa which has ceased for some days previous to discharge, but which recurs as the result of cold contracted after the final bath, or of thoughtless exposure after returning home, can only be indirectly debited to the hospital. No general practitioner pretends to say that otorrhœa or rhinorrhœa are unknown among scarlatinal cases treated at home, where of course there may be less risk of the rhinorrhoea recurring, simply because the discharge bath is less often indulged in. In either case the difficulty is overcome by keeping the patient in a disinfected room for a day or two after the discharge bath has been given. Especially in cold weather and in the case of girls with long hair, care should be taken in this way to avoid the risk of catching cold and setting up the catarrh afresh.

Another, though not a common cause of "return cases," is the germ-laden residual air in the lungs of patients sent out from a ward crowded with acute cases. This, if a cause, is certainly a diminishing one, seeing that in most fever hospitals convalescents are now removed to a separate ward. The difficulty is further overcome by isolating cases about to be discharged in a convalescent or discharge ward for a few days, as previously suggested after the final bath. In my opinion this plan is to be recommended, although the economist naturally asks: "Why further isolate, seeing that even without that discharge ward at least 97 per cent of cases go home without giving rise to any return cases?"

Overcrowding or the aggregation of acute cases as a cause of return cases is problematical, and at most can only act indirectly. It has been stated that overerowding tends to increase the proportion of 
septic complications, and naturally that would be a likely result. An increase in the number of beds in a ward during an epidemic does not always mean a corresponding increase in the number of nurses, and consequently mistakes are more readily made by an overworked staff. Apart therefore from the transmission of septic complications (of which more later), whether by direct or indirect means, the aggregation or overcrowding of acute cases is always to be discountenanced. Even when resorted to during epidemic times, under the impression that it may be the less of two evils, we find we cannot break the elementary laws of hygiene with impunity. At the same time overcrowding, or in other words, a vitiated atmosphere with consequent lowered vitality, is in my experience much more frequently met with when infectious cases are treated at home, and this by a sort of autointoxication. may explain the commencing rhinorrhoea exhibited by some children on admission. I fully agree with Priestley, Millard, and others, in preferring to admit only such cases as cannot be isolated at home, to overcrowding one's wards in the attempt to cope with every case reported during an epidemic.

It has been suggested that infection carried out from hospital has an "exalted virulence" compared with that contracted in the ordinary way. Such may be the case, although I have seen no reason to suspect that a " hospitalized strain" was being established. When many possibilities of infection exist, with only 1 or 2 per cent of return cases annually to draw conclusions from, one cannot speak from personal experience with certainty; but with such a classical example as Leicester before us, we should be able to find some evidence in support of the theory. You remember how 144 " carefully selected cases" were sentstraight to their homes "in all stages of the disease, and while very many must undoubtedly have still been highly infectious." Some may not have become "hospitalized," but if the theory of an exalted virulence were correct, one would hardly expect Dr. Priestley to report that " the type of the 1893 epidemic must have been very mild, as the death-rate (calculated on certificates) is only 3.5 per cent." The nearest approach which $I$ have seen to exalted virulence was when (under mistaken diagnosis) a case of measles was admitted into a scarlet fever ward and there contracted scarlatina. The fever was more than ordinarily severe; but I attributed the extra severity to the superimposed combination, and not to any exalted virulence inherent in the scarlet fever infection.

Before leaving this subject one might again ask, "Is the principle or the practice of hospital isolation most at fault in producing ' return cases,' or has either as much to do with their origin as outside and home influences"? My own opinion is that in a properly equipped 
hospital the number of such cases may be reduced to vanishing point, and that in many instances even hospital maladministration is debited with more than its own share of blame. The following facts have contributed to this conclusion. A certain hospital in the West Riding receives patients from some half-dozen different Sanitary Authorities: "A" Authority has not had a return case for years, although several hundred cases have been admitted; "B" has had 1 per cent; " $\mathrm{C}$ " has 2 ; and " $\mathrm{D}$ " 4 per cent. The same care is exercised over all ; or, if possible, greater care is taken in discharging cases from those districts where experience has shown the need for closest supervision. The obvious inference seems to be that home disinfection is more thorough in some districts than others, and that central even more than hospital administration requires investigation. and improvement. It does not follow that home disinfection has been efficient simply because no second case has developed among the inmates during the absence of the primary one; any more than it follows that a second case developing within a week of the return of the primary one from hospital is a return case. We all know how readily a book or a toy escapes disinfection only to be brought out on its owner's return, and yet this neglected toymay have more to do with the so-called return case than any "persistent infectivity" brought from hospital.

What sounds a very serious indictment of hospital isolation, has been made by Drs. Gayton, Millard, and others, in the following terms: "That otorrhœea and rhinorrhoea are propagable is proved by the fact that given a case of either kind, not infrequently it is communicated not only to patients in contiguity with the one affected, but to others in remote parts of the ward." The same subject has been touched upon when considering the evil effects of overcrowding. It was shown that a vitiated atmosphere had a baneful effect on the system generally, and when to that there is the additional danger locally of the direct transmission of streptococcic material from patient to patient, the position is pregnant with risk to every inmate of the ward. To me, however, the indictment is one of overcrowding and. mismanagement, which no one defends, rather than of the principle of hospital isolation. Millard says: "It is useless to urge that proper hospital administration, even though aided by every appliance that money can buy, should be able to obviate the danger here indicated." Theoretically one cannot absolutely obviate the danger, but I maintain that in practice we can. Understand that I wish neither to defend the system of overcrowding septic cases, nor to champion the cause of fever hospitals generally; but I do say that careful management in a properly equipped hospital can reduce to a minimum the risk of otorrhoea or rhinorrhoea being communicated either directly or 
indirectly. Dr. Curgenven, quoted by Millard; argued that "If we would never think of placing cases of wounds in a ward along with erysipelas or gangrene, neither should we place cases of scarlet fever in a ward with others suffering from scarlatinal otorrhoea." Quite so; but sometimes in a general hospital the surgeon has no choice, any more than the fever hospital superintendent. But do we always take the same care that the surgeon does? The surgeon makes certain that everything which has come in contact with the septic part is carefully and immediately destroyed; and surely we can take equal care to guard against the discharge from nose or ear becoming dried and disseminated throughout the ward. The same indictment might with. equal force be urged against consumptive sanatoria, and yet I think it has been demonstrated that such institutions can be carried on successfully without the atmosphere of the ward teeming with tubercle bacilli. So long as frail human nature has to be relied upon to maintain a constant fight against these septic germs, no half-hearted vigilance is sufficient. Nor do I wish to imply that hospital administration has reached a standard of perfection, although to be told that it is practically impossible to obviate the danger of septic complications is not the best stimulant to continued effort. Is it not better to have tried and failed, than never to have tried at all? There is no doubt but that the warning given by certain opponents of hospital isolation is opportune; and as showing that I am not prepared indiscriminately to defend the administrative practice of every hospital, I may mention that in a large Midland fever hospital it was the custom some years ago for two or three children to be bathed in the same water, for five or six to have their faces washed in the same basin and to be dried with the same towel, and, as if to make direct communicability a positive certainty, the same cloth or sponge went the round of the ward. I don't suppose this was done with the consent or knowledge of the Medical Superintendent, but I have the authority of nurses for saying that they were accustomed to this routine, and that they were never taught that there was danger in the dirty practice. In the same wards the nurse accompanying the doctor in his rounds carried a tongue depressor, which likewise went the round of the mouths of simple and septic with unvarying impartiality! I mention this fatalistic example purely as an object lesson, and sincerely trust I am not guilty of trying to take a mote out of a brother's eye and all the time have a beam in my own. If however, for economic or other reasons, an hospital is under-staffed or otherwise badly equipped, results are obtained which are not only worthless as a basis upon which to build a scientific theory, but damaging to institutions where the managers are more liberal and the administration more thorough. 
The next bugbear met by the opponents of hospital isolation is "mixed infections." For long this seemed to me a real difficulty. Cases of so-called post-scarlatinal diphtheria cropped up, which I could only account for by defective administration. The occurrence, for instance, of chicken-pox or measles in a scarlet fever ward is in rather a different category from post-scarlatinal diphtheria, and can only indirectly be considered due to maladministration. The possibility of the former combination should be averted by a reasonable amount of care being taken to prevent the patient being admitted except into a separate isolation ward. This of course implies the hearty co-operation of the private practitioner, who in notifying the scarlet fever would also draw the attention of the Medical Officer of Health to the fact that the invalid had also been exposed to other infection. The objection is that the private attendant might not be aware of the possibility of the minor infection, and so far as it goes that objection holds good. At the same time I cannot think many auch mixed infections would arise to damn a hospital if we secure the assistance of the general practitioner, and have at our disposal the necessary means for isolating questionable cases. There still remains, however, the more serious complication to which the terms "mixed infection" or "cross infection" specially refer. I mean the occurrence of diphtheria in a scarlet fever ward, or vice versa. A mistake in diagnosis may be the means by which the second infection is introduced, and this can only be overcome by the proper use of a receiving ward. The risk of cross infection from one ward to another is very slight, and can only arise when the administration is defective. It will still be urged that notwithstanding all precautions post-scarlatinal diphtheria will continue to occur, and I grant it may. The contingency however, is very remote if guard is kept upon a channel too little suspected or, it may be, too often neglected. The following experience will explain my meaning. During the early part of this year a case of post-scarlatinal diphtheria was detected in a large scarlet ward. So certain was I that no mismanagement on the part of the nurses or attendants was to blame for the case, that I decided to swab every scarlet throat showing the least exudation immediately on admission. At the end of a few months seven patients out of eighty-four scarlet fever admissions were declared by the county bacteriologist to have typical diphtheria bacilli in their throats. These cases happily were separately isolated, and no mixed infection has since occurred; but had they been treated at home a similar result could hardly be expected, and yet I question if home treatment would be debited with causing that mixed infection so conveniently called "an hospital phenomenon." 
It is foreign to my subject to discuss the problem as to whether scarlet fever and diphtheria can run their typical course simultaneously. That the Klebs-Löffler bacillus is often found in the throat of a patient suffering from typical scarlet fever is beyond question, and although scarlet fever is the predominating factor in the illness, it is undoubtedly possible for the diphtheria bacillus to show little or no virulence in one patient, and yet to set up post-searlatinal diphtheria in another.

Before leaving the subject of diphtheria complicating searlatina I would enter a caveat against adopting the views expressed by Dr. Thomas, in his recent report to the London Education Committee, with regard to the pseudo-diphtheria bacillus. Dr. Thomas states his opinion that the pseudo bacillus may safely be ignored. While this may be so among children with unimpaired resisting powers, I am sure you would have cause for regret were you to ignore that bacillus in a scarlet fever ward. At one time $I$ held a similar view, but sad experience convinced me that it was fatal policy to ignore or underestimate a foe. I have previously recorded my opinion that environment can so modify the pseudo or Hoffmann bacillus that it can assume the virulent characteristics and produce results indistinguishable from the true Klebs-Löffler bacillus. The grounds for this opinion are largely circumstantial; at the same time I think they are sug. gested by bacteriological results. For instance, we find true and pseudo bacilli in the same throat simultaneously; in another, one week we may find only true, next week only pseudo bacilli, and, subsequently, true or pseudo alternating; a case of scarlatina exhibiting pseudo bacillus will give rise to typical post-scarlatinal diphtheria in the patient in the adjoining bed; and two members of one family in a moorland cottage will show within a few days of each other the first pseudo and the second the true diphtheria bacillus, with no possibility of infection except from one to the other. It is because the same pronounced clinical symptoms are rarely found with the pseudo bacillus as with the true, that one is apt to overlook the existence of the milder type of infection, and yet I have this day seen tracheotomy performed on a child in whose throat and larynx only the bacillus Hoffmann could be found. We are however discussing an administrative rather than a bacteriological problem, and therefore I would urge that scarlatina complicated with any and every type of bacillus diphtheriæ be rigorously treated in separate isolation wards. If care were taken on admission to eliminate such mixed infections, my contention is that the possibility of post-scarlatinal diphtheria occurring in an ordinary scarlet fever ward would be a negligible quantity, even in that preventive system described by S. D. Marriott, of Nottingham, as a system " by the operation of which the infective 
sick are herded like dumb driven cattle in pest-houses miscalled isolation hospitals."

A writer, already quoted, prophesies that hospitals have had their day. With that I cannot agree. Nay, rather I feel sure the adverse criticism referred to above, by drawing attention to defects in management, will bring about an improvement in administrative detail, and as time and experience bring improved methods of treatment and an increased faith in the benefits to be derived therefrom, there will result an extension and not a diminution of hospital isolation.

\section{TYPHOID FEVER AT LINCOLN.}

An alarming outbreak of typhoid fever has occurred in Lincoln. The first case was notified on December 2 nd, but it was not until the 22 nd of the same month that the second case was reported. By January 10 th the number of cases had risen to eighteen, and by the middle of February about 600 cases had been notified. A sample of water examined in the middle of January showed that sewage pollution had taken place, and the public were at once requested to boil water to be used for drinking, and also milk. Samples of the water were taken subsequently by Dr. Reece, Inspector of the Local Government Board, and submitted to Prof. Klein. Typhoid bacilli are stated to have been found in the sample taken from the intake well connected with the river Witham. After filtration the bacillus was not discovered. The water supply of Lincoln is derived from surface water, the river Witham, the Ballast Pits, the Hartsholme Lake, the Pyke Drain, and the Prial Brook. The Corporation took over the waterworks in 1871. In 1883 the Medical Officer of Health called their attention to the wholly unsatisfactory state of the water supply. In 1885 the Local Government Board informed the Counoil that they "will incur a grave responsibility if disease should hereafter spread in the city." In the following year, a Local Government Board inspector drew the Council's attention to "the unsatisfactory state of the water supply." The Council, however, disregarded the warning.

In 1887 the Local Government Board again pointed out "the unsafe character of part of the water supply." The Medical Officer again pressed, in 1889 , for the matter to be taken up seriously, and again it was decided that there was " no ground for complaint." In 1892 a special committes reported that, though the water was not good, it was sufficient in quantity. No recommendation was made as to improving the quality. In 1892 a further notification from the Local Government Board was sent, and at last, in 1898, the Corporation undertook to consider the best methods of insuring an increased supply of water, and while it was felt that the process of filtration to which it was subjected would prevent any contamination, it was resolved to seek another supply by boring, and the contract for the operations was signed in 1902. Boring was carried out to a depth of 2,000 feet-which is said to be the greatest depth of any similar work in England ; but, unfortunately, the contractors lost one of their machines, and the operations have been delayed.

Unfortunately, both Dr. Harrison, the Medical Officer of Health, and the Sanitary Inspector were ill, the former with bronchitis, and the latter with typhoid, which has proved fatal. Nottingham, however, came to the assistance of Lincoln, by sending over Dr. Reece Jones and a Sanitary Inspector. 